\title{
Persistent air leak management in critically ill patients
}

\author{
Jonathan S. Kurman \\ Division of Pulmonary \& Critical Care, Medical College of Wisconsin, Milwaukee, WI, USA \\ Correspondence to: Jonathan S. Kurman, MD. Assistant Professor of Medicine, Director of Interventional Pulmonology, Division of Pulmonary \& \\ Critical Care, Medical College of Wisconsin, 8701 W Watertown Plank Rd, Milwaukee, WI 53226, USA. Email: jkurman@mcw.edu.
}

\begin{abstract}
Persistent air leak (PAL) is a challenging clinical entity, particularly in the setting of critical illness. It is a significant cause of morbidity, health care expenditure, and resource utilization. Data on its prevalence in the critically ill patient population are limited. Unique patient factors often necessitate an individualized approach. Guidelines on this subject are antiquated and do not specially address patients on mechanical ventilation. Critically ill patients may not be able to tolerate surgical intervention. Treatment in this population relies upon lung protective ventilation, various anecdotal modalities, chemical pleurodesis, autologous blood patching, and bronchoscopic insertion of endobronchial valves. Ventilation strategies center on rapid weaning and reduction of airway pressures. Anecdotal methods include implantable devices and chemical agents. Data on these modalities are limited to case reports. None have United States Food and Drug Administration (FDA) approval. The Spiration Valve System is FDA approved as a Humanitarian Device Exemption. Data on endobronchial valves are based on large case series, and only one small case series has focused exclusively on critically ill patients. The majority of valves in critically ill mechanically ventilated patients are used for non-FDA approved indications. Updated guidelines are desperately needed to ensure a standardized approach to this common clinical situation.
\end{abstract}

Keywords: Endobronchial valves; airway valves; persistent air leak (PAL); bronchoscopy; pneumothorax

Submitted Feb 11, 2021. Accepted for publication Jun 11, 2021.

doi: $10.21037 /$ jtd-2021-32

View this article at: https://dx.doi.org/10.21037/jtd-2021-32

\section{Introduction}

Persistent air leak (PAL) management is a challenging situation for many clinicians. Although it is a fairly common scenario, antiquated guidelines and lack of high-quality data contribute to variability in management that often depends upon local expertise and equipment. Myriad etiologies contribute to the complexity of standardization in management. Unique circumstances in each case often necessitate an individualized approach based on patient and clinician factors (1).

PAL in the setting of critical illness presents unique challenges that must be addressed in the context of the patient's overall condition (2). Concurrent infection and respiratory failure often complicate an already challenging situation. A patient's tenuous condition may preclude surgical intervention that would otherwise be the standard of care. PAL management in patients receiving mechanical ventilation deserves special attention. Minimally invasive strategies that are individualized are preferred in this particular patient population.

This review article will clearly elucidate key definitions on this subject, discuss how to classify the severity of an air leak, briefly review PAL epidemiology, identify risk factors, examine guidelines, and explore treatment options. The discussion of treatment strategies will focus on those applicable to critically ill patients who are often not surgical candidates. Hence, surgical strategies will not be covered.

\section{Definitions}

PAL refers to the continued air flow from the endobronchial tree to the pleural space. The specific terminology applied to this pathologic communication depends on its origin. An alveolar pleural fistula refers to a connection between the subsegmental bronchus or a more distal portion of the 


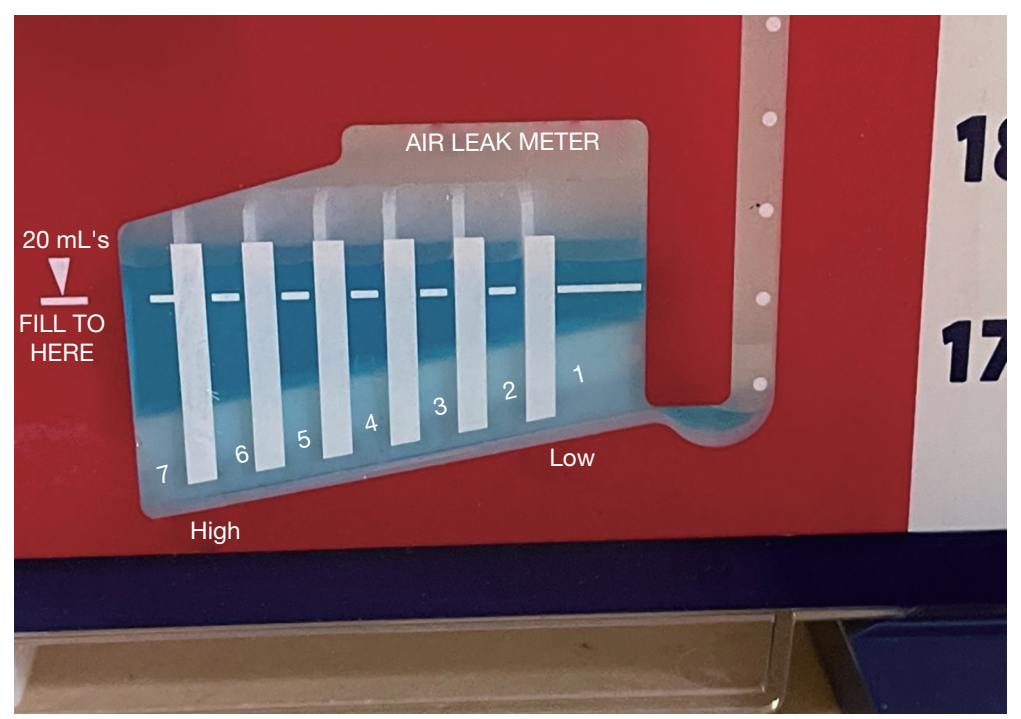

Figure 1 Water seal chamber of a pleural drainage system. The higher the numbered column through which bubbling occurs, the larger the air leak.

Table 1 Cerfolio classification of air leaks

\begin{tabular}{ll}
\hline Grade & Description \\
\hline Grade 1, FE & $\begin{array}{l}\text { During forced expiration only, typically } \\
\text { when asking the patient to cough }\end{array}$ \\
Grade 2, E & Expiration only \\
Grade 3, I & $\begin{array}{l}\text { Inspiration only } \\
\text { Grade 4, C }\end{array}$ \\
$\begin{array}{l}\text { Continuous bubbling present in the air leak } \\
\text { chamber during both inspiration and expiration }\end{array}$ \\
\hline
\end{tabular}

airway and the pleural space, whereas a bronchopleural fistula indicates a source at the segmental bronchus or a more proximal airway. Although precision in terminology is requisite for accurate research, management is generally the same regardless of the level of origin (3).

An air leak is classified as being persistent when it lasts beyond 5-7 days. This threshold was originally derived from surgical experience following pulmonary resection, where an air leak for several days was not uncommon. We have used a similar definition for air leak in mechanically ventilated ICU patients.

\section{Classification of severity}

An air leak can be identified by the presence of bubbling in the water seal chamber of a collection system connected to a tube thoracostomy. Numbered columns in the water seal chamber can be used to assess the severity of an air leak (Figure 1). A larger leak is indicated by bubbling in a higher numbered column.

The advent of digital drainage systems has allowed more precise and continuous quantification of the degree of air leak (4). Air flow into the collection system and pleural pressure difference is calculated in real time, thereby reducing the potential for interobserver variability that plagues air leak assessment with analog drainage systems.

Data have shown that a tube thoracostomy can be safely removed once an air leak is $<20 \mathrm{~mL} / \mathrm{min}$ (5). Utilization of a digital drainage device permits earlier removal of a pleural drain, which in turn decreases hospital length of stay (LOS) (6-8). These units will undoubtedly become more commonplace as affordability improves.

The Cerfolio system is the most commonly utilized classification method and categorizes leak severity based on the degree of air leak and the phase of respiration in which it occurs (Table 1) (9). Because it was designed for the postoperative setting, it is not necessarily applicable to patients in the intensive care unit (ICU), particularly those on mechanical ventilation.

\section{Epidemiology}

PAL may occur following barotrauma from mechanical ventilation, thoracic trauma, pneumothorax, pulmonary surgery, and pulmonary infection. In the critical care 
Table 2 Summary of the available guidelines on persistent air leak management

\begin{tabular}{lll}
\hline Year & Organization & Recommendation \\
\hline 2001 & American College of Chest Physicians & $\begin{array}{l}\text { Surgical evaluation for consideration of video-assisted thoracoscopic pleurodesis for } \\
\text { PAL following spontaneous pneumothorax }\end{array}$ \\
2010 & British Thoracic Society & Early thoracic surgical consultation \\
\hline
\end{tabular}

setting, barotrauma and pulmonary infection are common etiologies and may occur simultaneously. Surgical lung biopsy for further evaluation of ARDS may also lead to PAL in the ICU. Thirty percent of patients in one study developed PAL after open lung biopsy in the setting of ARDS (10).

The rate of PAL development is $26 \%$ and $24-46 \%$ after lobectomy and lung volume reduction surgery, respectively (11-13). A leak of greater than $50 \mathrm{~mL} / \mathrm{min}$ was found to be predictive of PAL development following lobectomy (14).

Although mechanical ventilation represents a clear risk factor for development of pneumothorax, the rate of consequential PAL is unknown. A study from 1986 identified an incidence rate for PAL of approximately two percent in patients on mechanical ventilation, but the average tidal volume was $14 \mathrm{~mL} / \mathrm{kg}$ (15). The rate of PAL development in the era of low tidal volume ventilation has not been reported but is assumed to be low given the relatively low rate with significantly higher airway pressures historically.

\section{Risk factors}

Risk factors for development of PAL have been identified following spontaneous pneumothorax, lobectomy, and lung volume reduction surgery. Common risk factors among these situations include age and the presence of underlying lung disease. Risk factors for lobectomy also include lower forced expiratory volume in one second, chronic obstructive pulmonary disease, female gender, smoking history, diabetes, chronic steroid use, and post-operative positive pressure ventilation (11-13,16-18).

Data are unavailable regarding risk factors specific to the critically ill patient population. Presumably some of the same factors mentioned above would impact these patients, but this has not yet been rigorously examined.

\section{Complications}

PAL represents a significant cause of morbidity, health care expenditure, and resource utilization in the post-operative and spontaneous pneumothorax populations. Data have shown that ICU readmission rate, hospital LOS, risk for pneumonia, and pleural space infections are all increased by the presence of PAL $(11,13)$. Because of the increased risk for soiling the pleural space, antimicrobial agents are typically initiated or continued, although there are limited data supporting this practice. This impact is only amplified in the ICU, where PAL may have even more devastating consequences given the already compromised condition of the patients. An older case series of 39 patients who developed PAL while on mechanical ventilation identified a mortality rate of $67 \%$ (15).

A PAL also has physiologic implications for both pleural mechanics and gas exchange. Pleural pressures, which are normally negative, rise in the setting of a pneumothorax but return to normal after insertion of a chest tube, even in the setting of an ongoing air leak (19). In patients with an ongoing air leak, inspiratory tidal volumes and tidal air flow are higher, while expiratory tidal volumes are lower. A marked respiratory alkalosis can develop as evacuated air is removed via the chest tube, thereby decreasing the concentration of $\mathrm{CO}_{2}$ in the alveoli and consequently increasing the diffusion gradient from the blood to the alveoli (19). Oxygenation can be affected (i.e., diminished) if pleural air is not evacuated rapidly enough and lung volumes or transpulmonary pressures are reduced (19).

\section{Guidelines}

Guidelines from British and American societies predate newer bronchoscopic PAL treatment modalities (Table 2). These guidelines also fail to address the unique circumstances surrounding PAL management in the setting of critical illness. British Thoracic Society guidelines from 2010 simply recommend early thoracic surgical consultation for management; bronchoscopic treatment options are not acknowledged (20). American College of Chest Physicians guidelines from 2001 only address PAL following spontaneous pneumothorax and recommend 
Table 3 Various anecdotal modalities used to treat PAL grouped into two general categories of implantable devices and chemical agents

Implantable devices
Watanabe spigots
Stents
Amplatzer plugs
Chemical agents
Thermal energy
Hemostatic substances
Submucosal injections
Tissue adhesives

PAL, persistent air leak.

surgical evaluation for consideration of video-assisted thoracoscopic pleurodesis (21). Bronchoscopic intervention is actually discouraged. Patients in the ICU may not be able to tolerate surgical intervention, so alternative solutions may be required.

\section{Treatment}

PAL management is a controversial area in general but even more so in the ICU setting where there are even less data to drive decision making. Antiquated guidelines do not address the critically ill patient population and do not endorse modern minimally invasive techniques. Many critically ill patients are not ideal surgical candidates, making their management even more challenging. Minimally invasive approaches are ideally suited to the ICU setting since they can be safely performed at bedside (22). Management techniques have evolved considerably since the first large case series of PAL in patients on mechanical ventilation was published in 1986 (15). A small-bore chest tube is generally sufficient. If subcutaneous emphysema develops, however, a second chest tube or a larger bore tube may be required to allow for sufficiently rapid egress of air. Suction should be minimized. This is often not possible, however, when patients are mechanically ventilated.

Knowing when to intervene with an air leak is paramount. Trend, duration, and volume of the leak are the primary factors that need to be considered. Trend refers to the whether the air leak is stable, increasing, or decreasing over time. Duration refers to how long the leak has been present. Volume refers to the degree of leak, which can be assessed using an analog or digital collection system (6). Put simply, an air leak is less likely to spontaneously resolve if there is a large leak that has been present for a longer period of time and is getting worse (23).

\section{Ventilation adjustments}

PAL management in the setting of critical illness should start with the ventilator. Ventilation strategies can be used to mitigate risk of PAL occurrence and decrease duration of the leak once it has developed. Weaning from the ventilator as rapidly as possible while minimizing tidal volume, positive end-expiratory pressure, and the number of positive-pressure breaths will facilitate PAL resolution by promoting closure of the pleural defect (24). Cho et al. demonstrated a lower risk of PAL development in patients with acute respiratory distress syndrome undergoing open lung biopsy with lower peak airway pressure, lower tidal volume, and use of pressure-cycled ventilation (10). In fact, the risk of PAL was reduced by almost half for every $5 \mathrm{cmH}_{2} \mathrm{O}$ the peak airway pressure was decreased. Neither high frequency ventilation nor an independent lung ventilation strategy have been shown to be consistently effective at expediting resolution of a PAL (24).

\section{Anecdotal strategies}

Numerous case reports and case series exist on a wide variety of anecdotal approaches to PAL management (25-32). These strategies can be grouped into implantable devices and chemical agents (Table 3). The former category includes Watanabe spigots, stents, and Amplatzer occluding devices, while the latter contains thermal treatments, hemostatic substances, submucosal injections, and tissue adhesives. Data on these techniques are limited and must be interpreted with caution given the potential for bias. While none of these modalities are approved by the United States Food and Drug Administration (US FDA) for this indication, Watanabe spigots are a widely accepted treatment modality in Japan (26).

\section{Chemical pleurodesis}

Chemical pleurodesis involves the instillation of sclerosants into the pleural space with the intention of inducing an inflammatory reaction designed to achieve pleurodesis via fusion of the two pleural surfaces (33). In order for this modality to be effective, there must be apposition of the 

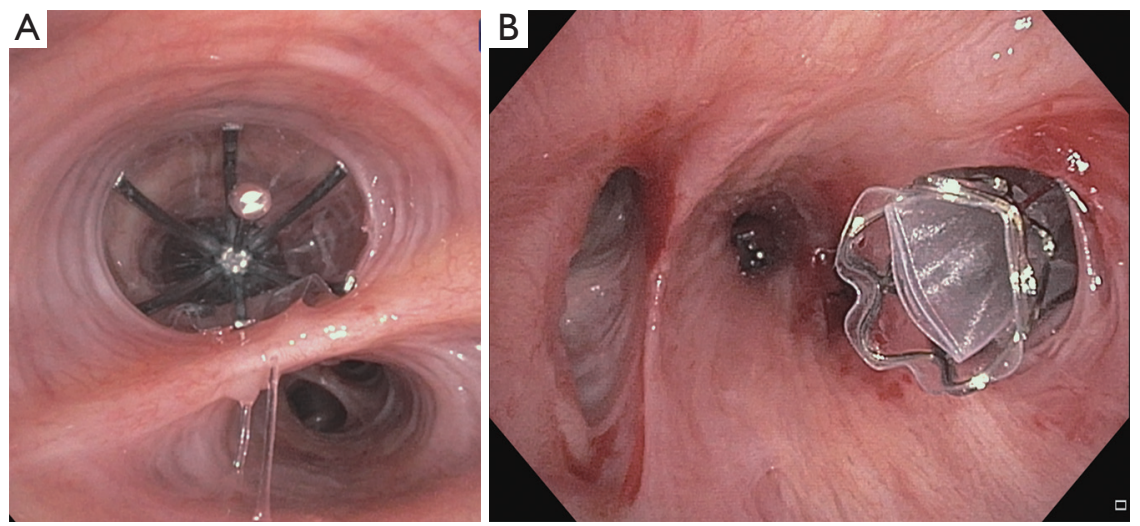

Figure 2 The two types of EBVs. (A) Spiration ${ }^{\circledR}$ endobronchial valve in a segmental airway in the right middle lobe. This valve has an umbrella-like conformation; (B) Zephyr ${ }^{\circledR}$ endobronchial valve, which has a duckbill shape. This valve is not yet US FDA approved for PAL management. EBV, endobronchial valve; PAL, persistent air leak.

visceral and parietal pleural surfaces. Introduction of these agents can, in rare instances, induce severe lung injury, which may be poorly tolerated in someone who is already critically ill. While talc is one of the most commonly used agents for this purpose, other medications that have been utilized include doxycycline, bleomycin, minocycline, and tetracycline. Several retrospective studies have demonstrated success with these agents, although none were specifically in the critically ill patient population (12).

\section{Blood patch pleurodesis}

Autologous blood patch pleurodesis involves phlebotomizing $50-100 \mathrm{~mL}$ of peripheral venous blood followed by its instillation through an existing tube thoracostomy (34). The chest tube is then flushed and clamped or elevated to permit adequate dwell time. This method has been utilized for more than three decades in the United States and is supported by data demonstrating a high success rate with PAL after surgical lung resection or spontaneous pneumothorax (35-37). After instillation, the blood covers the pleural defect, creating a seal. It also results in some degree of pleural inflammation, which may be sufficient to precipitate pleurodesis. For pleural symphysis to occur, the two pleural surfaces must be in contact.

\section{One-way bronchial valves}

One-way bronchial valves represent a novel minimally invasive option for PAL treatment and the only bronchoscopic modality with US FDA approval. Although they were originally developed for patients with severe emphysema as an alternative to bronchoscopic lung volume reduction (BLVR), their application for other uses has become apparent. In 2005, Snell et al. reported the first case of using these valves for a PAL (38). Although there are two endobronchial valves currently approved by the US FDA for BLVR, only one of these (Spiration Valve System, Olympus, Inc.) has been granted approval for PALs following lobectomy, segmentectomy, or lung volume reduction surgery as a Humanitarian Device Exemption (HDE) (Figure 2) (39). The other valve (Zephyr, Pulmonx, Inc.) is reportedly actively pursuing an equivalent indication but is currently only approved for BLVR. A HDE applies to conditions that affect less than 4,000 patients per year in the United States and for which no comparable device is available.

Both valves are one-way devices that allow air and other debris to move proximally into the central airways but block ventilation distally. In theory, this limits airflow through the fistula and permits apposition of the two edges of the pleural defect so that healing can occur. Because of this, valves are a temporizing intervention designed to be removed after approximately 6 weeks. Removal is performed by grasping the central rod of the Spiration valve with a cupped forcep, pulling it onto the end of the bronchoscope, and removing everything en bloc. Insertion is also performed with a flexible bronchoscope. The valve must be loaded into the deployment catheter, which is then introduced through the working channel of a bronchoscope with at least a $2.8-\mathrm{mm}$ working channel. A breath hold is generally performed, and then the valve is unsheathed in the appropriate airway. More 
detailed instructions for proper deployment technique is beyond the scope of this manuscript.

Before valve insertion occurs, identification of the culprit airway and valve sizing must be performed. Locating the culprit airway or airways is often the most challenging and time-consuming part of the procedure. Post-surgical cases are typically the simplest scenario. Other etiologies, such infection and barotrauma, are often more complex due to lack of localization at the start of the case and the increased potential for collateral ventilation leading to multilobar contribution to the leak (3). These causes are even more likely to be present in an ICU setting. Valve sizing is determined using a carefully calibrated balloon and explained in detail elsewhere (40).

The most common methodology employed to identify the involved airways is sequential balloon occlusion, whereby a balloon is used to occlude airways starting with the largest airway and proceeding distally to the segmental or subsegmental level. The author recommends using the standard Olympus B5-2C $13 \mathrm{~mm}$ diameter low pressure balloon included with the air leak procedure kit to ensure complete occlusion of lobar and central airways. This technique was first described in 1977 by Ratliff et al. (41). After each inflation, the balloon must remain in place for approximately 5 breath cycles before deflation and relocation so that existing air in that airway has the opportunity to be completely expelled. The patient must be carefully monitored for hemodynamic instability, especially during occlusion of more proximal airways. Premature deflation of the balloon can cause a false negative assessment of a potentially involved airway. Other techniques for identifying the culprit airway include insufflation and insertion of a dye, such as methylene blue, through the chest tube and observing for emergence within the endobronchial tree (42). Another method involves the use of a pressure transducer catheter (Chartis, Pulmonx, Inc.) (43). Upon occlusion of an airway, continued air flow beyond approximately two minutes generally indicates the presence of collateral ventilation and/or a pleural fistula.

Both valves are composed of a Nitinol (combination of nickel and titanium) framework and then either a polyurethane (Spiration ${ }^{\mathrm{TM}}$ ) or silicone $\left(\right.$ Zephyr $^{\mathrm{TM}}$ ) covering. Both types are designed to move and flex with the airway as it changes conformation during the respiratory cycle. The Spiration valve is umbrella shaped and is secured in place via small anchors on its distal aspect, while the radial expansile force prevents the duckbill-shaped Zephyr valve from migrating. Both valves are present in 4 sizes to accommodate airways of various diameters.

While valves are generally well tolerated, complications are possible. These may include pneumonia, acute worsening of hypoxia, valve malpositioning, and expectoration. Acute worsening of hypoxia may occur due to ventilation and perfusion mismatch before hypoxic vasoconstriction can compensate. This situation is rare, typically short-lived, and rarely requires valve extraction.

Data supporting bronchial valves is more robust than for the anecdotal approaches discussed earlier but is still generally limited to large case series. In 2009, Travaline et al. (44) demonstrated a $93 \%$ success rate and a $15 \%$ complication rate in 40 patients treated with the Zephyr valve for PAL. Chest tubes were able to be removed after an average of 7.5 days. The first case series of the Spiration valve for PAL was published in 2011 and had a 100\% success rate after an average of 4.5 days following the procedure without any procedure-related complications (45). In the largest multicenter study of Spiration valves to date, Gilbert et al. identified improvement in the air leak in $56 \%$ of patients (46). In the largest single-center case series to date ( $\mathrm{N}=60$ patients), $80 \%$ of patients were able to have their chest tubes removed (47).

In the two largest case series referenced above, 70-85\% of patients had bronchial valves inserted for non-FDA approved indications $(46,47)$. This deviation from the officially approved use stems from limited poor-quality data, outdated guidelines, and the desire to avoid the significant morbidity associated with PAL (48). For this same reason, valves may be inserted prior to postoperative day 5. Data have shown that COPD is an independent risk factor for worse outcomes in the setting of PAL (49). Thus, bronchial valves are often utilized earlier in this population to expedite resolution of the leak in an attempt to prevent further morbidity.

Similar rationale may be relevant to valve use in the setting of critical illness, where off-label indications may also prevail. For example, one case report highlights the use of an endobronchial valve to facilitate weaning from extracorporeal membrane oxygenation in a patient with acute respiratory distress syndrome and PAL (50). This phenomenon, where the majority of cases are for offlabel use, is becoming increasingly common even in noncritically ill patients and reflects antiquated guidelines. The paucity of up-to-date guidelines leads to profound variability in management that hinders data collection and ultimately limits advancement of knowledge in this area (48). Thus far, data are limited to large case series. A randomized 
trial [Valves Against Standard Therapy (ClinicalTrials. gov Identifier: NCT02382614)] was aborted prematurely because of poor enrollment. Insufficient data were collected for statistical analysis.

\section{Conclusions}

Lung protective ventilatory strategies that limit airway pressures should be employed in the setting of critical illness to avoid development of PAL and expedite resolution once one has occurred. Liberation from the ventilator should be prioritized. Chemical pleurodesis and autologous blood patch pleurodesis remain viable management strategies in certain patients. To date, only one small case series using bronchial valves for PAL has exclusively contained critically ill patients (22). Focused analysis of this population is imperative given their unique circumstances, such as the frequent requirement for mechanical ventilation. Data from ongoing randomized trials will hopefully permit development of a more standardized approach for this challenging clinical scenario.

\section{Acknowledgments}

Funding: None.

\section{Footnote}

Provenance and Peer Review: This article was commissioned by the editorial office, Fournal of Thoracic Disease for the series "Interventional Pulmonology in the Intensive Care Unit Environment". The article has undergone external peer review.

Conflicts of Interest: The author has completed the ICMJE uniform disclosure form (available at https://dx.doi. org/10.21037/jtd-2021-32). The series "Interventional Pulmonology in the Intensive Care Unit Environment" was commissioned by the editorial office without any funding sponsorship. JSK served as the unpaid Guest Editor of the series. JSK reports personal fees from Level Ex, personal fees from Medtronic, other from Pinnacle Biologics, personal fees from Biodesix; personal fees from American Medical Forum, and outside the submitted work. The author has no other conflicts of interest to declare.

Ethical Statement: The author is accountable for all aspects of the work in ensuring that questions related to the accuracy or integrity of any part of the work are appropriately investigated and resolved.

Open Access Statement: This is an Open Access article distributed in accordance with the Creative Commons Attribution-NonCommercial-NoDerivs 4.0 International License (CC BY-NC-ND 4.0), which permits the noncommercial replication and distribution of the article with the strict proviso that no changes or edits are made and the original work is properly cited (including links to both the formal publication through the relevant DOI and the license). See: https://creativecommons.org/licenses/by-nc-nd/4.0/.

\section{References}

1. Revelo A, Keshishyan S, Epelbaum O, et al. Diagnostic and therapeutic challenges in managing persistent air leaks. J Thorac Dis 2018;10:522-8.

2. Yarmus L, Feller-Kopman D. Pneumothorax in the critically ill patient. Chest 2012;141:1098-105.

3. Kurman JS, Hogarth DK. Minimally invasive persistent air leak management. AME Med J 2018;3:80.

4. Rathinam S, Bradley A, Cantlin T, et al. Thopaz Portable Suction Systems in Thoracic Surgery: an end user assessment and feedback in a tertiary unit. J Cardiothorac Surg 2011;6:59.

5. Cerfolio RJ, Varela G, Brunelli A. Digital and smart chest drainage systems to monitor air leaks: the birth of a new era? Thorac Surg Clin 2010;20:413-20.

6. Aldaghlawi F, Kurman JS, Lilly JA, et al. A Systematic Review of Digital vs Analog Drainage for Air Leak After Surgical Resection or Spontaneous Pneumothorax. Chest 2020;157:1346-53.

7. Brunelli A, Salati M, Refai M, et al. Evaluation of a new chest tube removal protocol using digital air leak monitoring after lobectomy: a prospective randomised trial. Eur J Cardiothorac Surg 2010;37:56-60.

8. Pompili C, Detterbeck F, Papagiannopoulos K, et al. Multicenter international randomized comparison of objective and subjective outcomes between electronic and traditional chest drainage systems. Ann Thorac Surg 2014;98:490-6; discussion 496-7.

9. Cerfolio RJ. Advances in thoracostomy tube management. Surg Clin North Am 2002;82:833-48, vii.

10. Cho MH, Malhotra A, Donahue DM, et al. Mechanical ventilation and air leaks after lung biopsy for acute respiratory distress syndrome. Ann Thorac Surg 2006;82:261-6. 
11. DeCamp MM, Blackstone EH, Naunheim KS, et al. Patient and surgical factors influencing air leak after lung volume reduction surgery: lessons learned from the National Emphysema Treatment Trial. Ann Thorac Surg 2006;82:197-206; discussion 206-7.

12. Liberman M, Muzikansky A, Wright CD, et al. Incidence and risk factors of persistent air leak after major pulmonary resection and use of chemical pleurodesis. Ann Thorac Surg 2010;89:891-7; discussion 897-8.

13. Stolz AJ, Schutzner J, Lischke R, et al. Predictors of prolonged air leak following pulmonary lobectomy. Eur J Cardiothorac Surg 2005;27:334-6.

14. Brunelli A, Cassivi SD, Salati M, et al. Digital measurements of air leak flow and intrapleural pressures in the immediate postoperative period predict risk of prolonged air leak after pulmonary lobectomy. Eur J Cardiothorac Surg 2011;39:584-8.

15. Pierson DJ, Horton CA, Bates PW. Persistent bronchopleural air leak during mechanical ventilation. A review of 39 cases. Chest 1986;90:321-3.

16. Asamura H, Naruke T, Tsuchiya R, et al. Bronchopleural fistulas associated with lung cancer operations. Univariate and multivariate analysis of risk factors, management, and outcome. J Thorac Cardiovasc Surg 1992;104:1456-64.

17. Jiang L, Jiang G, Zhu Y, et al. Risk factors predisposing to prolonged air leak after video-assisted thoracoscopic surgery for spontaneous pneumothorax. Ann Thorac Surg 2014;97:1008-13.

18. Li SJ, Fan J, Zhou J, et al. Diabetes Mellitus and Risk of Bronchopleural Fistula After Pulmonary Resections: A Meta-Analysis. Ann Thorac Surg 2016;102:328-39.

19. Mentzer SJ, Tsuda A, Loring SH. Pleural mechanics and the pathophysiology of air leaks. J Thorac Cardiovasc Surg 2018;155:2182-9.

20. MacDuff A, Arnold A, Harvey J, et al. Management of spontaneous pneumothorax: British Thoracic Society Pleural Disease Guideline 2010. Thorax 2010;65 Suppl 2:ii18-31.

21. Baumann MH, Strange C, Heffner JE, et al. Management of spontaneous pneumothorax: an American College of Chest Physicians Delphi consensus statement. Chest 2001;119:590-602.

22. Mahajan AK, Verhoef $P$, Patel SB, et al. Intrabronchial valves: a case series describing a minimally invasive approach to bronchopleural fistulas in medical intensive care unit patients. J Bronchology Interv Pulmonol 2012;19:137-41.

23. Wood DE, Cerfolio RJ, Gonzalez X, et al. Bronchoscopic management of prolonged air leak. Clin Chest Med 2010;31:127-33, Table of Contents.

24. Kempainen RR, Pierson DJ. Persistent air leaks in patients receiving mechanical ventilation. Semin Respir Crit Care Med 2001;22:675-84.

25. Andreetti C, Ibrahim M, Ciccone A, et al. Autologus platelet gel for the management of persistent alveolar fistula after lung resection. Minerva Chir 2010;65:695-9.

26. Kaneda H, Minami K, Nakano T, et al. Efficacy and long-term clinical outcome of bronchial occlusion with endobronchial Watanabe spigots for persistent air leaks. Respir Investig 2015;53:30-6.

27. Lim AL, Kim CH, Hwang YI, et al. Bronchoscopic ethanolamine injection therapy in patients with persistent air leak from chest tube drainage. Tuberc Respir Dis (Seoul) 2012;72:441-7.

28. Mehta HJ, Malhotra P, Begnaud A, et al. Treatment of alveolar-pleural fistula with endobronchial application of synthetic hydrogel. Chest 2015;147:695-9.

29. Sharpe DA, Dixon C, Moghissi K. Thoracoscopic use of laser in intractable pneumothorax. Eur J Cardiothorac Surg 1994;8:34-6.

30. Takaoka K, Inoue S, Ohira S. Central bronchopleural fistulas closed by bronchoscopic injection of absolute ethanol. Chest 2002;122:374-8.

31. Thistlethwaite PA, Luketich JD, Ferson PF, et al. Ablation of persistent air leaks after thoracic procedures with fibrin sealant. Ann Thorac Surg 1999;67:575-7.

32. Watanabe S, Watanabe T, Urayama H. Endobronchial occlusion method of bronchopleural fistula with metallic coils and glue. Thorac Cardiovasc Surg 2003;51:106-8.

33. Mierzejewski M, Korczynski P, Krenke R, et al. Chemical pleurodesis - a review of mechanisms involved in pleural space obliteration. Respir Res 2019;20:247.

34. Ibrahim IM, Elaziz MEA, El-Hag-Aly MA. Early Autologous Blood-Patch Pleurodesis versus Conservative Management for Treatment of Secondary Spontaneous Pneumothorax. Thorac Cardiovasc Surg 2019;67:222-6.

35. Chambers A, Routledge T, Bille A, et al. Is blood pleurodesis effective for determining the cessation of persistent air leak? Interact Cardiovasc Thorac Surg 2010;11:468-72.

36. Ploenes T, Kyritsis I, Mardanzai K, et al. A Prospective Study Investigating Blood Patch Pleurodesis for Postoperative Air Leaks After Pulmonary Resection. J Surg Res 2020;255:240-6.

37. Robinson CL. Autologous blood for pleurodesis in recurrent and chronic spontaneous pneumothorax. Can J 
Surg 1987;30:428-9.

38. Snell GI, Holsworth L, Fowler S, et al. Occlusion of a broncho-cutaneous fistula with endobronchial one-way valves. Ann Thorac Surg 2005;80:1930-2.

39. Abu-Hijleh M, Styrvoky K, Anand V, et al. Intrabronchial Valves for Air Leaks After Lobectomy, Segmentectomy, and Lung Volume Reduction Surgery. Lung 2019;197:627-33.

40. Mahajan AK, Khandhar SJ. Bronchoscopic valves for prolonged air leak: current status and technique. J Thorac Dis 2017;9:S110-S115.

41. Ratliff JL, Hill JD, Tucker H, et al. Endobronchial control of bronchopleural fistulae. Chest 1977;71:98-9.

42. Mahajan AK, Doeing DC, Hogarth DK. Isolation of persistent air leaks and placement of intrabronchial valves. J Thorac Cardiovasc Surg 2013;145:626-30.

43. Huang X, Ding L, Xu H. Bronchoscopic valve placement for the treatment of persistent air leaks. Medicine (Baltimore) 2018;97:e0183.

44. Travaline JM, McKenna RJ Jr, De Giacomo T, et al. Treatment of persistent pulmonary air leaks using endobronchial valves. Chest 2009;136:355-60.

Cite this article as: Kurman JS. Persistent air leak management in critically ill patients. J Thorac Dis 2021;13(8):5223-5231. doi: $10.21037 /$ jtd-2021-32
45. Gillespie CT, Sterman DH, Cerfolio RJ, et al.

Endobronchial valve treatment for prolonged air leaks of the lung: a case series. Ann Thorac Surg 2011;91:270-3.

46. Gilbert CR, Casal RF, Lee HJ, et al. Use of OneWay Intrabronchial Valves in Air Leak Management After Tube Thoracostomy Drainage. Ann Thorac Surg 2016;101:1891-6.

47. Bermea RS, Miller J, Wilson WW, et al. One-Way Endobronchial Valves as Management for Persistent Air Leaks: A Preview of What's to Come? Am J Respir Crit Care Med 2019;200:1318-20.

48. Kurman JS, Hogarth DK. Management of persistent air leaks: a shifting paradigm. Shanghai Chest 2018;2:26.

49. Videm V, Pillgram-Larsen J, Ellingsen O, Andersen G, Ovrum E. Spontaneous pneumothorax in chronic obstructive pulmonary disease: complications, treatment and recurrences. Eur J Respir Dis 1987;71:365-71.

50. Ghiani A, Hansen M, Tsitouras K, et al. Endobronchial One-Way Valve Therapy Facilitates Weaning from Extracorporeal Membrane Oxygenation in a Patient with ARDS and Persistent Air Leak. Case Rep Crit Care 2018;2018:9736217. 